\title{
Lotus of fantoom?
}

\section{Realiteitsbeleving bij simulatieonderwijs in acute zorg}

\author{
R.J.A.M. Brendel • J.B.N. de Best • C.M. de With
}

Samenvatting Achtergrond: Binnen de acute zorg wordt simulatieonderwijs vormgegeven door gebruikmaking van een lotus en/of een fantoom. Een lotus is een acteur die ziektebeelden uitbeeldt. Een fantoom is een geavanceerd computergestuurde pop waarbij parameters kunnen veranderen, afhankelijk van de behandeling.

Doel: Het aantonen van het verschil in realiteitsbeleving tussen training/toetsing met fantoom of training/ toetsing met een lotus in combinatie met fantoom.

Methode: Gedurende vijf weken zijn bij toetsen de deelnemers $(n=25)$ at random in groep 1 (toets met fantoom) of groep 2 (toets met lotus in combinatie met fantoom) geplaatst. Alle deelnemers kregen dezelfde casus. Na de toets vulde elke deelnemer een vragenlijst in over realiteitsbeleving van de simulatie. De beoordelaars vulden telkens naast de standaardscorelijst een vragenlijst in met betrekking tot de observeerbare aspecten van realiteitsbeleving.

Resultaten: De totaalscores van groep 1 (fantoom) en groep 2 (lotus met fantoom) zijn vergeleken. Met een onafhankelijke t-toets is een significant verschil gevonden tussen de totaalscores van deelnemers in groep 1 $(\mathrm{M}=3.10 ; \mathrm{SD}=.691)$ en groep $2(\mathrm{M}=3.96 ; \mathrm{SD}=.804)$; $\mathrm{t}(23)=-2.852, \mathrm{p}=.009$. Ook laten de totaalscores van de beoordelaars een significant verschil zien, dat is berekend met een Mann-Whitney-U-test $(\mathrm{Z}-2.484 ; \mathrm{p}=.013)$.

Conclusie en discussie: Trainen en/of toetsen met een lotus in combinatie met een fantoom lijkt te verkiezen boven het gebruik van een fantoom alleen. De realiteitsbeleving met de combinatie is hoger. Aangezien het een kleine steekproef betreft, willen de auteurs dit onderzoek vervolgen. (Brendel RJAM, Best JBN de, With CM de. Lotus of fantoom? Realiteitsbeleving bij simulatieonderwijs in acute zorg. Tijdschrift voor Medisch Onderwijs 2007;26(3):111-117.)

\section{Aanleiding}

In het acute zorgonderwijs wordt veel gebruikgemaakt van simulaties om beroepsspecifieke vaardigheden aan te leren. ${ }^{1-8}$ Voor de transfer van vaardigheden van een gesimuleerde setting naar de realiteit, is het belangrijk ${ }^{9}$ dat trainingssituaties herkenbaar en reëel zijn voor studenten.

Bij simulatieonderwijs wordt vaak gebruikgemaakt van fantomen. Een voordeel van simulaties met fantomen is dat deelnemers kunnen oefenen en fouten kunnen maken, zonder dat dit negatieve gevolgen heeft voor de patiënt. ${ }^{2}$ Een ander voordeel is dat de indruk ontstaat dat een echte patiënt behandeld wordt. ${ }^{4}$ Studenten noemen echter beperkingenvoor wat betreft de 'klinische realiteit', ondanks de geavanceerde technologieën die bij fantomen terug te vinden zijn. ${ }^{1}$ De voordelen die genoemd worden in bovenstaande onderzoeken, hebben uitsluitend betrekking op het ontwikkelen van de technische aspecten van de competenties. Daarnaast is integratie van technische vaardigheden met communicatieve en andere professionele vaardigheden van belang. ${ }^{10}$ Tijdens trainingen kan ook gebruikgemaakt worden van een fantoom in combinatie met een lotus. ${ }^{11}$ Een lotus is een acteur de getraind is om de rol van de patiënt te spelen. Een voordeel van deze combinatie is dat de student de patiënt tijdens het proces kan volgen op een zo realistisch mogelijke manier.

Ook binnen de Regionale Ambulance Voorziening provincie Utrecht (RAVU) wordt gebruik gemaakt van simulaties tijdens vaardigheidstrainingen en vaardigheidstoetsen waarbij fantomen en lotussen worden gecombineerd. Het doel van vaardigheidstraining (of toetsing) is een patiëntencasus te simuleren, waarbij ambulancezorgverleners moeten overgaan tot 
daadwerkelijke diagnosestelling en behandeling. Een belangrijk uitgangspunt bij de RAVU is dat de werkelijke situatie zoveel mogelijk benaderd wordt tijdens de training, zodat ambulancezorgverleners worden aangezet tot het vertonen van gedrag dat zij in een reële situatie ook zouden moeten vertonen.

De meeste simulaties starten met een lotus, omdat in de realiteit de meeste slachtoffers aanspreekbaar zijn. Het verrichten van lichamelijk onderzoek en het afnemen van de anamnese vereisen communicatie en een juiste houding. Indien er handelingen moeten worden verricht, welke niet op de lotus kunnen worden uitgevoerd, schakelt men over op een fantoom. Het wordt zowel door cursisten als instructeurs als een nadeel ervaren dat het scenario wordt 'stilgezet': de al verrichte handelingen en aangesloten diagnostische middelen worden overgezet van lotus naar fantoom, waarna het scenario met fantoom wordt vervolgd.

In 2003 is door de RAVU één van de meest geavanceerde fantomen aangeschaft: een fantoom dat lijkt op een mens en waarop diverse lichaamsfuncties kunnen worden nagebootst. Volgens de fabrikant maakt dit fantoom het werken met lotussen overbodig. Inmiddels is een ruime tijd gewerkt met dit fantoom en de ervaringen waren niet onverdeeld positief.

$\mathrm{Er}$ is besloten onderzoek te doen naar de realiteitsbeleving van ambulancezorgverleners tijdens vaardigheidstraining en -toetsing om te bepalen welke simulatie beter toegepast kon worden: simulatie met alleen een fantoom of een simulatie met een combinatie van lotus en fantoom.

\section{Literatuuronderzoek}

Veel (Amerikaanse) onderzoeken richten zich op de inzet van fantomen en het nut daarvan binnen het vaardigheidsonderwijs. In bijna al deze onderzoeken worden de positieve effecten genoemd van het trainen met een fantoom. Daarbij wordt wel opgemerkt dat het inzetten van een fantoom vergeleken wordt met het traditionele onderwijs (colleges). Tevens wordt beschreven dat een fantoom juist beperkingen kan hebben met betrekking tot de realiteitswaarde, ${ }^{1}$ bijvoorbeeld als het gaat om de huidsamenstelling of de huidkleur. De meeste onderzoeken geven aan dat er betere resultaten worden bereikt in situaties waarbij gebruik gemaakt wordt van een fantoom, maar er wordt niet aangegeven op welke aspecten dan betere resultaten worden behaald. Het gaat voornamelijk steeds om scores op het gebied van technische aspecten. Slechts een beperkt aantal onderzoeken ${ }^{3,11}$ richt zich op het vergelijken van het trainen van vaardigheden met behulp van een fantoom en van lotussen. De gekozen onderzoeksvraag is bijzonder, omdat het zich niet richt op technische aspecten, maar op de realiteitsbeleving van de gesimuleerde situatie. Met een hogere realiteitsbeleving wordt de transfer naar de werkelijke situatie bevorderd. ${ }^{9}$

\section{Methode}

Gedurende vijf weken zijn bij toetsingen de ambulancezorgverleners $(\mathrm{n}=25)$ at random in groep 1 (met fantoom; $\mathrm{n}=12$ ) of in groep 2 (lotus in combinatie met fantoom; $n=13$ ) geplaatst. De deelnemers kregen allen dezelfde casus waarbij het slachtoffer niet aanspreekbaar was. $\mathrm{Na}$ de toets vulde elke ambulancezorgverlener een vragenlijst in over de realiteitsbeleving van de simulatie (5-puntsschaal; geheel oneens tot helemaal mee eens). De beoordelaars vulden telkens een scorelijst in (3-puntsschaal; onvoldoende, voldoende en goed), die standaard wordt gebruikt bij landelijke toetsingen van ambulancezorgverleners en is ontwikkeld en gevalideerd door de Stichting Opleiding en Scholing Ambulancezorgverleners (SOSA). Daarnaast vulden zij ook een voor dit onderzoek ontwikkelde vragenlijst in met betrekking tot de observeerbare aspecten van realiteitsbeleving (5puntsschaal; geheel oneens tot helemaal mee eens).

Het begrip realiteitsbeleving is na literatuurstudie en in samenwerking met een 'subject matter expert' geoperationaliseerd in vijf dimensies met elk weer één of meerdere indicatoren. Deze indicatoren zijn verwerkt tot Likert items. De vijf dimensies zijn:

1. Communicatie (observeerbare aspecten; dimensies die ook terugkomen in de vragenlijst van de beoordelaars).

2. Houding (observeerbare aspecten; dimensies die ook terugkomen in de vragenlijst van de beoordelaars).

3. Bewust zijn van de situatie.

4. Besluitvaardigheid.

5. Klinische vaardigheden (observeerbare aspecten; dimensies die ook terugkomen in de vragenlijst van de beoordelaars).

De vragenlijsten voor de deelnemers en de beoordelaars zijn na een pilot $(n=6)$ getest op betrouwbaarheid door berekening van de Cronbachs Alpha. De realiteitsbeleving liet voor beide vragenlijsten een interne consistentie zien (respectievelijk .95 en .77). Onafhankelijke ttoetsen zijn uitgevoerd om de mate van realiteitsbeleving tussen deelnemers uit groep 1 en groep 2 met elkaar te vergelijken. Dit is ook gedaan voor de totaalscores van de vragenlijsten van de beoordelaars van groep 1 en groep 2. Verder zijn er correlaties berekend, door middel van Pearsons correlatie, voor het verband tussen het 
Tabel 1. Vragenlijst en resultaten deelnemers.*

\begin{tabular}{|c|c|c|c|c|}
\hline & & $\begin{array}{r}\text { Groep } \\
1\end{array}$ & $\begin{array}{r}\text { Groep } \\
2\end{array}$ & p-waarde \\
\hline 1. & $\begin{array}{r}\text { De simulatie was realistisch genoeg dat ik de noodzaak voelde tot het snel onder controle krijgen } \\
\text { van de vitale functies. }\end{array}$ & 3.83 & 4.38 & .077 \\
\hline 2. & $\begin{array}{r}\text { De simulatie was realistisch genoeg dat ik mij verantwoordelijk voelde voor het correct behandelen } \\
\text { van de patiënt. }\end{array}$ & 3.33 & 4.31 & .019 \\
\hline 3. & De simulatie was realistisch genoeg dat het mij uitnodigde contact te zoeken met de patiënt. & 2.25 & 3.85 & .001 \\
\hline 4. & De simulatie was realistisch genoeg dat het mij uitnodigde om mijn handelingen toe te lichten. & 2.92 & 3.85 & .022 \\
\hline 5. & De simulatie was realistisch genoeg dat het mij uitnodigde mijn beslissingen uit te leggen. & 3.00 & 3.92 & .037 \\
\hline 6. & De simulatie was realistisch genoeg dat ik het gevoel had dat de patiënt mij kon horen. & 2.50 & 3.54 & .019 \\
\hline 7. & $\begin{array}{l}\text { De simulatie was realistisch genoeg dat het mij uitnodigde overleg te hebben met mijn collega (hier } \\
\text { soms docent). }\end{array}$ & 3.58 & 4.31 & .088 \\
\hline 8. & De samenwerking met mijn collega (hier soms docent) verliep zoals in een reële situatie. & 3.58 & 4.08 & .288 \\
\hline 9. & De simulatie was realistisch genoeg zodat ik mezelf betrokken voelde bij de patiënt. & 2.92 & 3.92 & .021 \\
\hline 10. & De simulatie was realistisch genoeg zodat ik de patiënt respectvol bejegende. & 3.17 & 3.92 & .126 \\
\hline 11. & De simulatie kwam reëel op mij over. & 2.83 & 3.62 & .094 \\
\hline 12. & De waarneming van de kleur van de patiënt gaf mij het gevoel dat de patiënt vitaal bedreigd was. & 2.08 & 3.85 & .002 \\
\hline 13. & De waarneming van de hartslag van de patiënt is realistisch. & 3.91 & 3.69 & .509 \\
\hline 14. & $\begin{array}{r}\text { De waarneming van de toestand van de huid van de patiënt gaf mij het gevoel dat de patiënt vitaal } \\
\text { bedreigd was. }\end{array}$ & 2.17 & 3.77 & .001 \\
\hline 15. & Ik heb gehandeld zoals ik in een reële situatie ook zou doen. & 3.25 & 3.92 & .122 \\
\hline 16. & De simulatie belemmerde mij in het nemen van beslissingen. & 2.83 & 2.00 & .061 \\
\hline 17. & In deze simulatie heb ik besluiten genomen die ik in een reële situatie niet zou nemen. & 2.67 & 2.00 & .077 \\
\hline 18. & $\begin{array}{l}\text { De uitvoering van de verpleegtechnische vaardigheden was vergelijkbaar met de uitvoering in een } \\
\text { reële situatie. }\end{array}$ & 3.27 & 4.00 & .10 \\
\hline 19. & Ik vind de training in deze vorm van simulatie bijdragen aan beter functioneren in de praktijk. & 3.42 & 4.31 & .02 \\
\hline 20. & $\begin{array}{r}\text { De training in deze vorm van simulatie geeft mij meer vertrouwen voor mijn handelen in de } \\
\text { praktijk. }\end{array}$ & 3.42 & 3.92 & .24 \\
\hline
\end{tabular}

* De gemiddelden per item per groep. Groep 1: training met fantoom, groep 2: training met Lotus in combinatie met fantoom. De in vet gedrukte getallen geven aan dat het verschil tussen beide groepen voor dat item statistisch significant is.

communicatie- en houdingsdeel van de standaardscorelijsten en de dimensies communicatie en houding van de vragenlijsten van de beoordelaars.

\section{Resultaten}

Er is een statistisch significant verschil gevonden tussen de totaalscores van de deelnemers in groep $1(\mathrm{M}=3.10$; $\mathrm{SD}=.691)$ en groep $2(\mathrm{M}=3.96 ; \mathrm{SD}=.804) ; \mathrm{t}(23)$ $=2.852, \mathrm{p}=.009$. De effectgrootte is .26 . Elke dimensie laat een statistisch significant verschil zien:

1. Communicatie: $\mathrm{t}(23)=-2,645 ; \mathrm{p}=.014$.

2. Houding: $\mathrm{t}(23)=-2,127 ; \mathrm{p}=.044$.

3. Bewustzijn: $\mathrm{t}(23)=-2,348 ; \mathrm{p}=.028$.

4. Besluitvaardigheid: $\mathrm{t}(23)=-2,133 ; \mathrm{p}=.044$.

5. Klinische vaardigheden: $\mathrm{t}(23)=-3,146 ; \mathrm{p}=.005$.

Voor de vragenlijsten en scores per item verwijzen we u naar tabel 1.

De totaalscores van de beoordelaars laten ook een statistisch significant verschil zien ten voordele van groep 2. Dit is berekend met een Mann-Whitney-U-test $(\mathrm{Z}=2.484 ; \mathrm{p}=.013)$, aangezien de variantie bij groep 1 groter is dan bij groep 2. Voor de dimensie houding is een statistisch significant verschil gevonden $(Z=-2,840$; $\mathrm{p}=.005)$. Dit geldt niet voor de dimensie communicatie $(Z=-1,548 ; p=.113)$ en klinische vaardigheid $(Z=-, 231$; $\mathrm{p}=.817)$. Voor de vragenlijsten en scores per item verwijzen we u naar tabel 2.

Het communicatiedeel van de scorelijstenen de vragenlijst voor de beoordelaars correleert positief significant op de onderdelen communicatie met collega $(r=.704)$ en communicatie met slachtoffer $(r=.549)$. Er is ook een positief significante correlatie te zien tussen het deel beroepshouding van de standaardscorelijsten de dimensie houding van de vragenlijsten $(r=.723)$.

De opmerkingen van de deelnemers laten voor beide simulaties voor- én nadelen zien:

Voordelen fantoom alleen:

1. "Bij gebruik van alleen een fantoom hoef je niet halverwege over te schakelen van lotus op een pop. Je kunt dus in de simulatie blijven. Ik vind dat een voordeel." 
Tabel 2. Vragenlijst en resultaten instructeurs.*

\begin{tabular}{|c|c|c|c|c|}
\hline & & $\begin{array}{r}\text { Groep } \\
1\end{array}$ & $\begin{array}{r}\text { Groep } \\
2\end{array}$ & $\begin{array}{r}\text { Mann-Whitney-U- } \\
\text { test }\end{array}$ \\
\hline \multirow[t]{2}{*}{1.} & De ambulancezorgverlener zocht contact met de patiënt. & 2.75 & 4.15 & $Z=-2.243$ \\
\hline & & & & $\mathrm{p}=. \mathbf{0 2 5}$ \\
\hline \multirow[t]{2}{*}{2.} & De ambulancezorgverlener lichtte zijn handelingen toe. & 2.67 & 3.92 & $Z=-1.911$ \\
\hline & & & & $\mathrm{p}=.056$ \\
\hline \multirow[t]{2}{*}{3.} & De ambulancezorgverlener heeft zijn besluiten toegelicht. & 3.17 & 4.00 & $Z=-1.470$ \\
\hline & & & & $\mathrm{p}=.142$ \\
\hline \multirow[t]{2}{*}{4.} & De ambulancezorgverlener heeft voldoende overleg gehad & 4.25 & 4.54 & $Z=-.549$ \\
\hline & met zijn collega. & & & $\mathrm{p}=.583$ \\
\hline \multirow[t]{2}{*}{5.} & De ambulancezorgverlener heeft de patiënt respectvol bejegend. & 3.50 & 4.46 & $Z=-2.165$ \\
\hline & & & & $\mathrm{p}=. \mathbf{0 3 0}$ \\
\hline \multirow[t]{2}{*}{6.} & De ambulancezorgverlener bleef patiënt met $\mathrm{u}$ aanspreken. & 2.83 & 4.00 & $Z=-\mathbf{2 . 1 1 4}$ \\
\hline & & & & $\mathrm{p}=. \mathbf{0 3 4}$ \\
\hline \multirow[t]{2}{*}{7.} & De ambulancezorgverlener gebruikte geen onnodige verkleinwoorden. & 2.92 & 4.46 & $Z=-2.649$ \\
\hline & & & & $\mathrm{p}=. \mathbf{0 0 8}$ \\
\hline \multirow[t]{2}{*}{8.} & De ambulancezorgverlener stapte niet over de zorgvrager heen. & 3.17 & 4.42 & $Z=-\mathbf{2 . 0 5 9}$ \\
\hline & & & & $\mathrm{p}=. \mathbf{0 3 9}$ \\
\hline \multirow[t]{2}{*}{9.} & De ambulancezorgverlener heeft de zorg efficiënt uitgevoerd. & 4.00 & 4.08 & $\mathrm{Z}=-.231$ \\
\hline & $\begin{array}{r}\text { Dit blijkt uit de juiste handelingen op het juiste moment op de juiste manier } \\
\text { uitvoeren. }\end{array}$ & & & $\mathrm{p}=.817$ \\
\hline \multirow[t]{2}{*}{10.} & De ambulancezorgverlener leek betrokken bij de patiënt. & 3.33 & 4.38 & $Z=-\mathbf{1 . 9 9 5}$ \\
\hline & & & & $\mathrm{p}=.046$ \\
\hline \multirow[t]{2}{*}{11.} & Er was sprake van voldoende samenwerking tussen verpleegkundige en chauffeur. & 4.33 & 4.62 & $\mathrm{Z}=.-470$ \\
\hline & & & & $\mathrm{p}=.638$ \\
\hline
\end{tabular}

* De gemiddelden per item per groep. Groep 1: training met fantoom, groep 2: training met Lotus in combinatie met fantoom. De in vet gedrukte getallen geven aan dat het verschil tussen beide groepen voor dat item statistisch significant is.

\section{Voordelen combinatie lotus en fantoom:}

1. "Door gebruik van lotus en schmink, toch nog enigszins benadering van de werkelijkheid. Toch meer sprake van contact tussen patiënt en ambulanceteam."

2. "Geen gevoel met een voorwerp als pop."

3. "Het blijft lastig praten tegen een pop."

\section{Nadelen combinatie lotus en fantoom:}

1. "Het is moeilijk om bij oefening met een lotus te bedenken dat het geen spel is. Eigenlijk zie je zo dat de lotus niet echt wat heeft."

2. " Het blijft moeilijk de gegeven en verkregen parameters te vertalen naar de lotus."

\section{Conclusie en discussie}

Uit dit onderzoek, waarbij werd onderzocht of de werkelijke situatie het dichtst benaderd wordt met een fantoom alleen (groep 1) of met een fantoom en lotus (groep 2), blijkt dat de mate van realiteitsbeleving bij de deelnemers van groep 2 voor elke dimensie significant hoger is dan bij de deelnemers van groep 1. De beoordelaars laten alleen bij de dimensie houding een significant verschil zien tussen groep 1 en 2. Blijkbaar nodigt een lotus meer uit tot respectvolle bejegening en betrokkenheid dan een fantoom. Dit aspect is van groot belang omdat voor het plaatsvinden van transfer het nodig is dat studenten betrokken zijn bij de situatie. ${ }^{9}$ De studenten zullen zich verantwoordelijk gaan voelen voor de besluiten die ze nemen. Dit ultieme gevoel van verantwoordelijkheid creëert een actief leermodel, wat de basis is voor een krachtige ervaringsgerichte leermethode. ${ }^{9}$ Uit het onderzoek van Lee et al. ${ }^{3}$ blijkt dat fantomen de realiteitswaarde van het acute zorgonderwijs verhogen, aangezien de fysiologische kenmerken gemanipuleerd kunnen worden. Het ging in dat onderzoek voornamelijk om de technische vaardigheden en de betrokkenheid van de student werd niet gemeten. Uit het huidige onderzoek blijkt dat het verschil in realiteitsbeleving voornamelijk wordt aangetroffen bij de dimensie houding. Dit laat zien dat een gecombineerde simulatie meer uitnodigt tot respectvolle bejegening en betrokkenheid. Een beperking van het experiment in dit onderzoek is dat de steekproef klein is $(n=25)$. Weliswaar is er een significant verschil gevonden, met een grote effect size, voor de totaalscores 
van realiteitsbeleving (deelnemers) en realiteitswaarde (beoordelaars), maar genoemde beperking nodigt uit het onderzoek te vervolgen.

\section{Belangenconflict: geen gemeld.}

Financiële ondersteuning: geen gemeld.

\section{Summary}

Background: Standardised patients and/or manikins are used for training and assessment of paramedics in the Netherlands. Standardised patients are actors, trained to portray certain symptoms and syndromes. Advanced computer-controlled manikins can display varying parameters, depending on the treatment received.

Aim: To investigate any difference between the use of a manikin only or a manikin combined with a standardised patient for training and assessment with regard to how realistic the simulation is as perceived by participants.

Method: During a five-week period all paramedics taking part in a yearly assessment, consisting of the same patient case $(n=25)$ were randomly allocated to group 1 (manikin only) or group 2 (standardised patient and manikin). The participants completed a questionnaire in which they indicated how realistic they thought the simulation had been. The assessors completed a questionnaire concerning observable aspects of how realistic the participants had perceived the simulation to be.

Results: An independent t-test revealed a significant difference between the total scores of the participants in group 1 (manikin) $(\mathrm{M}=3.10 ; \mathrm{SD}=.691)$ and group 2 (SP and manikin) $(\mathrm{M}=3.96$; $\mathrm{SD}=.804) ; \mathrm{t}(23)=-2.852, \mathrm{p}=.009$. The assessors' total group scores also differed significantly (Mann-Whitney-U-test: $Z=-2,484$; $\mathrm{p}=.013)$.

Discussion and conclusion: The use of a combination of a simulated patient and a manikin seems to be preferable to that of a manikin only. Participants perceived the combination as more realistic. Because of the small sample of this study, further research will be undertaken among a larger sample. (Brendel RJAM, De Best JBN, De With CM. How realistic are simulations in emergency medicine training? Dutch Journal of Medical Education 2007;26(3):111-117.)

\section{Literatuur}

Good ML. Patient simulation for training basic and advanced clinical skills. Med Educ 2003;37(suppl.1):14-21.

Kneebone RL. Twelve tips on teaching basic surgical skills using simulation and multimedia. Med Teach 1999;21(6):571-5.

Lee SK, Pardo M, Gaba D, Sowb Y, Dicker R, Straus, et al. Trauma assessment training with a patient simulator: a prospective, randomized study. J Trauma 2003;55(4):651-7.

Mönk S, Baldering HJ, Vollmer J, Buggenhagen H, Heinrichs W. Patientensimulation. Notfall \& Rettungsmedizin 1999;2 (5):297-306.

Alinier G, Hunt WB, Gordon R. Determining the value of simulation in nurse education: studey design and initial results. Nurse Education in Practice 2004;4(3):200-7.

Barsuk D, Berkenstadt H, Stein M, Lin M, Ziv A. Advanced patient simulators in pre-hospital trauma management training - the trainees' perspective. Harefuah 2003;142(2):87-90, 160 .

Holcomb JB, Dumire RD, Crommett JW, Stamateris CE, Fagert MA, Clevland JA, et al. Evaluation of trauma team performance using an advanced human patient simulator for resuscitation training. J Trauma 2002;52(6):1078-85.

Gilbart MK, Hutchison CR, Kusimano MD, Regher G. A computer-based trauma simulator for teaching trauma management skills. Am J Surg 2000;179(3):223-8.

Harless WG, Zier MA, Smith JE, Dube R, Duncan RC, Ayers WR. TIME project interactive patient simulations: experiential learning in the medical school classroom. Journal of Medical Education Technologies 1992;2(4):3-8.

Kneebone R, Nestel D, Yadollahi F, Brown R, Nolan C, Durack J, et al. Assessing procedural skills in context: exploring the feasibility of an Integrated Procedural Performance Instrument (IPPI). Med Educ 2006;40:1105-14.

Greenberg R, Loyd G, Wesley G. Integrated simulation experiences to enhance clinical education. Med Educ 2002;36:1109-10. 